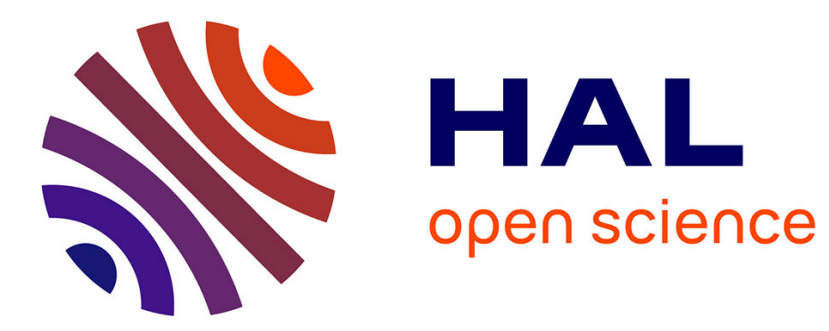

\title{
Older and younger adults' strategies in sensorimotor tasks: Insights from Fitts' pointing task.
}

Céline Poletti, Rita Sleimen-Malkoun, Jean-Jacques Temprado, Patrick Lemaire

\section{- To cite this version:}

Céline Poletti, Rita Sleimen-Malkoun, Jean-Jacques Temprado, Patrick Lemaire. Older and younger adults' strategies in sensorimotor tasks: Insights from Fitts' pointing task.. Journal of Experimental Psychology: Human Perception and Performance, 2015, 41, pp.542 - 555. 10.1037/xhp0000033 . hal-01432331v2

\section{HAL Id: hal-01432331 \\ https: / hal-amu.archives-ouvertes.fr/hal-01432331v2}

Submitted on 17 Feb 2017

HAL is a multi-disciplinary open access archive for the deposit and dissemination of scientific research documents, whether they are published or not. The documents may come from teaching and research institutions in France or abroad, or from public or private research centers.
L'archive ouverte pluridisciplinaire HAL, est destinée au dépôt et à la diffusion de documents scientifiques de niveau recherche, publiés ou non, émanant des établissements d'enseignement et de recherche français ou étrangers, des laboratoires publics ou privés. 


\title{
Older and Younger Adults' Strategies in Sensorimotor Tasks: Insights From Fitts' Pointing Task
}

\author{
Céline Poletti, Rita Sleimen-Malkoun, Jean-Jacques Temprado, and Patrick Lemaire \\ Aix-Marseille Université and Centre National de la Recherche Scientifique
}

\begin{abstract}
We investigated how young and older adults differ in sensorimotor tasks. Two groups of participants (young and older adults) performed discrete Fitts' tasks in which 4 levels of difficulty (ID) were used, resulting from either the manipulation of the size of the target $\left(\mathrm{ID}_{\mathrm{W}}\right)$ or of the distance between home and target positions $\left(\mathrm{ID}_{\mathrm{D}}\right)$. Kinematic analysis allowed distinguishing 4 different types of strategies used to reach the target, on the basis of the existence and the nature of submovements. Results showed that the repertoire of strategies was significantly smaller in older than in young participants. In addition, the frequency of use of the different strategies varied with participants' age. Specifically, the most frequent strategies used by older participants included submovements, while those used by young participants did not include submovements. The differences observed between young and older adults were independent of whether ID was manipulated via target size or movement distance. Finally, age-related differences in strategy performance were found. These results have important implications for furthering our understanding of aging effects in sensorimotor tasks. They also illustrate the usefulness of a strategy approach in a domain where it had never been formally used before.
\end{abstract}

Keywords: aging, strategic variations, Fitts' law, sensorimotor mechanisms

Aging is associated with decline in cognitive and motor performance. However, although general principles of cognitive aging are now well identified, much less is known about these changes in the sensorimotor domain, in particular with respect to strategic variations in movement organization.

The study of quantitative changes in motor functioning has been predominantly accomplished through two main lines of investigations. On the one hand, a neurophysiological perspective, which has led to study task-related control mechanisms - that is, the ability to control the multiple dimensions of postural, locomotion, coordination, grip, or aiming tasks - as if they were fully specific and independent from each other (e.g., see Spirduso, 2005, for an overview). On the other hand, a psychological perspective that has revealed the existence of generalizable changes in informationprocessing resources across tasks. In this latter perspective, behavioral slowing and movement variability have attracted much inter-

This article was published Online First March 9, 2015.

Céline Poletti, Aix-Marseille Université and CNRS, LPC UMR 7290 and ISM, UMR 7287; Rita Sleimen-Malkoun, Aix-Marseille Université and CNRS, ISM, UMR 7287 and INS, UMR INSERM 1106; Jean-Jacques Temprado, Aix-Marseille Université and CNRS, ISM UMR 7287; Patrick Lemaire, Aix-Marseille Université and CNRS, Institut Universitaire de France, LPC, UMR 7290.

This research was supported by grants from the Agence Nationale de la Recherche (Grant ANR-13-BSH2-0005-01 and Grant ANR-2010-BLAN1912-01).

Correspondence concerning this article should be addressed to JeanJacques Temprado, Institut des Sciences du Mouvement, Aix-Marseille Université, Faculté des Sciences du Sport, 163 Route de Luminy, BP 910, 13288 Marseille, Cedex, France. E-mail: jean-jacques.temprado@univamu.fr est with reaction time (RT) and aiming tasks being widely used since they allow the separation between central and peripheral control mechanisms. Accordingly, aging has been found to decrease mainly the speed of central processing. Such decrease is reflected in the slowing of both RTs (Falkenstein, Yordanova, \& Kolev, 2006; Kolev, Falkenstein, \& Yordanova, 2006; Light \& Spirduso, 1990; Yordanova, Kolev, Hohnsbein, \& Falkenstein, 2004) and movement times (e.g., Ketcham, Seidler, Van Gemmert, \& Stelmach, 2002; Rey-Robert, Temprado, \& Berton, 2011; Temprado et al., 2013). Specifically, older adults take longer time to both plan (i.e., to initiate the movement after an imperative signal) and restructure movement execution (i.e., to make online corrections) than young adults do. Age-related increase in variability of movement execution has also been shown to be a critical property of sensorimotor aging (Meyer, Abrams, Kornblum, Wright, \& Smith, 1988; Schmidt, Zelaznik, Hawkins, Frank, \& Quinn, 1979; Slifkin \& Newell, 1999; Sosnoff \& Newell, 2006). It is assumed to result from neural noise that interferes with the transmission of information within the central nervous system (Gregory, 1957; Welford, 1981). However, in contrast to cognitive tasks, only moderate generalizability has been found in the variability of movements across motor tasks (Sosnoff \& Newell, 2006).

More recently, research on sensorimotor aging has taken two main directions. On the one hand, interest has been given to the interdependence between (higher) cognitive and (lower) sensorimotor processes increase during aging (e.g., Li \& Dinse, 2002; Li \& Lindenberger, 2002). Specifically, it has been shown that during aging the involvement of cognitive processes in movement control becomes increasingly important (e.g., Heuninckx, Wenderoth, Debaere, Peeters, \& Swinnen, 2005; see Schäfer, Huxhold, \& Lindenberger, 2006, for a review). In addition, based on empirical comparisons of age-related slowing in RTs and movement tasks, it has been suggested that decrease in information-processing rate 
might be a common cause to cognitive and motor slowing (see Sleimen-Malkoun, Temprado, \& Berton, 2013, for supporting evidence). On the other hand, quantitative, chronometric assessments of motor response have been completed by the study of qualitative changes in movement execution; that is, of the different strategies used to achieve task goals. For instance, pioneering work on upright standing postural tasks showed that to control the amount of body sway, at least three possible strategies can be used (i.e., ankle, hip, and stepping strategies) (Horak \& Nashner, 1986). However, although strategic variations presumably exist in different motor tasks (e.g., locomotion, coordination, aiming), a conceptual framework is lacking to formalize the invariant features of age-related strategic variations in the sensorimotor domain, and until now, only scattered descriptions of strategy use have been undertaken (e.g., Bennett, Elliott, \& Rodacki, 2012; Dounskaia, Wisleder, \& Johnson, 2005; Elliott, Hansen, Mendoza, \& Tremblay, 2004; Elliott, Hansen, \& Grierson, 2009; Fradet, Lee, \& Dounskaia, 2008; Ketcham et al., 2002; Lyons, Hansen, Hurding, \& Elliott, 2006).

The present research was conducted to contribute to our knowledge about determiners of age-related differences and similarities in strategic variations of sensorimotor behaviors. We pursue this goal in the context of the Fitts' discrete aiming task and in continuity with the two-component model of unimanual movement control introduced more than a century ago by Woodworth (1899), and that has stimulated since most contemporary research on movement control (Meyer et al., 1988; see Elliott, Helsen, \& Chua, 2001, 2010 for theoretical developments). Several reasons motivated this choice. First of all, control processes used during aiming movements in Fitts' task are representative of those used in different motor tasks (e.g., posture, locomotion). Second, aiming movements are prone to age-related differences in the management of speed-accuracy trade-off, which may arise from a coalition of factors (e.g., decrease in information processing rate, loss of muscle strength) and be reflected in both chronometric measures (movement times) and movement kinematics.

Before outlining the logic of the present work, we first briefly review previous findings on young and older adults' performance in the Fitts' task under varying experimental conditions. Then, we discuss the usefulness of a strategy approach to further our understanding of sensorimotor behaviors and aging effects therein.

\section{Previous Findings in the Fitts' Task}

Fitts' task mimics functional conditions under which participants have to adopt a compromise between speed and accuracy to achieve a given goal. It consists in performing rapid aiming movements from a starting location toward a target (see Figure 1).

The difficulty of the Fitts' task can be easily manipulated by varying the width (W) and/or distance (D) of the target (Fitts, 1954; Fitts \& Peterson, 1964). Difficulty increases with decreasing the size of the target and/or with increasing the distance between the starting and target positions. The index of difficulty (ID, in bits) of the task has been quantified as a logarithmic function of the physical dimensions of the target ID $=\log _{2}(2 \mathrm{D} / \mathrm{W})$. Movement time (i.e., the time to reach the target) is linearly related to ID according to the following relation: $\mathrm{MT}=a+b \times \mathrm{ID}$, with $a$ and $b$ empirically determined constants. This linear relation-so-called Fitts' law_quantifies the efficiency function of the information-

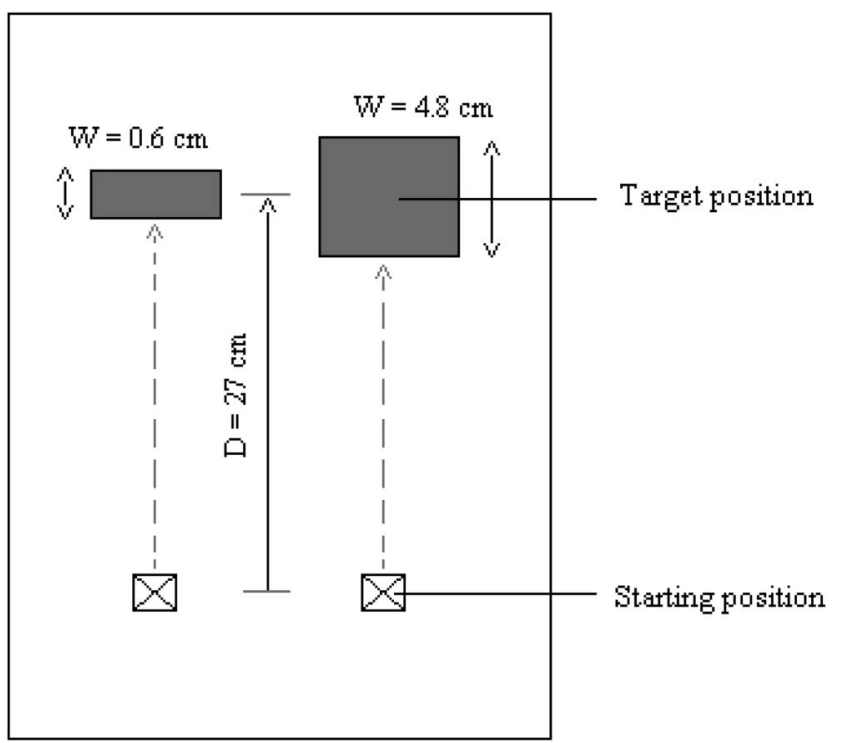

Figure 1. Illustration of the Fitts' task with two different IDs (3.5 and 6.5 bits) obtained via manipulation of the target width (i.e., $0.6 \mathrm{~cm}$ and $4.8 \mathrm{~cm}$ ), under a target-distance condition of $27 \mathrm{~cm}$.

processing system in the central nervous system (i.e., informationprocessing rate): The steeper the slope, the longer it takes to process a fixed amount of information.

Fitts' law has proven to be robust in both young and older participants (Rey-Robert, Temprado, Lemaire, \& Berton, 2012; Temprado et al., 2013). However, several studies showed that movement durations lengthened more in older than in young participants as ID increased (Haaland, Harrington, \& Grice, 1993; Ketcham et al., 2002; Rey-Robert et al., 2012; Teeken et al., 1996; Temprado et al., 2013; Welford, Norris, \& Shock, 1969; York \& Biederman, 1990). As a consequence, the slope of Fitts' law is generally smaller in young than in older adults (Rey-Robert et al., 2012; Sleimen-Malkoun et al., 2013; Temprado et al., 2013). Previous studies found that, compared to increasing movement accuracy (W manipulation), increasing movement amplitude (D manipulation) results in a steeper ID-MT slope (Sleimen-Malkoun, Temprado, Huys, Jirsa, \& Berton, 2012; Temprado et al., 2013). This suggests that D manipulation globally imposes greater processing demands to the cognitive-motor system. Such difference between the effects of $\mathrm{W}$ and $\mathrm{D}$ is enhanced during aging.

It is currently admitted that there are two distinct kinds of sensorimotor processes involved in Fitts task. These processes can be identified on the basis of kinematic analyses; that is, through the decomposition of movement into two phases, with the instant of peak velocity being the division point (Huys, Fernandez, Bootsma, \& Jirsa, 2010; Rey-Robert et al., 2012; Sleimen-malkoun et al., 2012). The duration of the acceleration phase (AT), corresponding to the time between movement start and peak velocity, results from processes operating in feed-forward (open-loop) and reflects central programming of force impulses. The duration of the deceleration phase (DT), starting from peak velocity and ending with movement stop in the target, results from online adaptations of central commands on the basis of processing of multiple sensory information feedbacks in the central nervous system. Previous 
studies showed that people lengthen both AT and DT when ID is manipulated via target distance, but lengthen DT only when the width of the target is manipulated (e.g., Rey-Robert et al., 2011; Temprado et al., 2013). With regards to aging, previous results showed that increase in $\mathrm{ID}_{\mathrm{D}}$ (index of difficulty resulting from the manipulation of the distance between home and target positions) results in multiplicative slowing of both AT and DT in young adults whereas increase in $\mathrm{ID}_{\mathrm{W}}$ (index of difficulty resulting from the manipulation of the size of the target) results in additive slowing of AT and multiplicative slowing of DT in older participants (Temprado et al., 2013).

Following Woodworth (1899), in Fitts' tasks it has been proposed to divide the movement in an initial impulse phase (characterized by a rapid movement that brings the limb near the target) and an online control phase (during which the target is approached). Several models have been proposed in this respect (see Elliott et al., 2001, 2010, for reviews). The most influential was the optimized submovement model developed by Meyer et al. (1988) implying the presence of a ballistic primary submovement and an optional secondary corrective submovement. Based on this twocomponent model, a further distinction has been introduced by Dounskaia et al. (2005) to qualify movement kinematics in goaldirected aiming tasks. This distinction concerns the presence of three different secondary submovement types (i.e., Type 1, 2, and 3) during the secondary movement phase. Type 1 secondary submovements are used to correct for overshooting; Type 2 submovements are used to correct for undershooting; and Type 3 submovements refer to finest corrections involved in the progressive deceleration to stop within the target. Each of these different submovements has a specific kinematic signature (Dounskaia et al., 2005).

The traditional interpretation of the occurrence of submovements is that they take part in corrective processes, which ensure spatial accuracy at the expense of slowness of movement execution (Elliott et al., 2004; Fradet et al., 2008; Lyons et al., 2006). In this perspective, the different submovement types can be considered as specific strategies to ensure optimal speed-accuracy tradeoff, as a function of task constraints (i.e., target size and target distance). In support of this hypothesis, it has been shown that, in discrete aiming movements, decreasing target size is usually accompanied by a relative shortening of initial impulse and a concomitant increase in the occurrence of submovements (Dounskaia et al., 2005; Ketcham et al., 2002; Meyer et al., 1988). It has also been demonstrated that the occurrence of submovements increases in older adults (Fradet et al., 2008; Ketcham et al., 2002), presumably as a result of age-related increase in neuromuscular noise, decrease in muscle strength, and altered efficiency of sensory feedback processing.

In summary, discrete Fitts' tasks seem appropriate to study the effects of tasks properties and age on strategic variations in goaldirected movements. However, a theoretical framework is still lacking in the sensorimotor domain to afford a whole picture of strategic variations in discrete Fitts' aiming tasks. Indeed, in most previous studies, only the occurrence of submovements (or lack thereof) was considered meaningful for understanding control processes. Thus, detailed analyses from a "strategy" perspective of the occurrence of the different submovement types, their frequency distribution, and the efficiency of their execution have been scarcely undertaken. In addition, it is unknown whether and how young and older adults differ in terms of the use and the execution of each strategy as a function of task difficulty. The present study is a step forward in this direction.

\section{A Strategy Perspective to Investigate Sensorimotor Behaviors}

To better understand strategic variations in goal-directed movements while participants accomplish Fitts' tasks, we adopted the theoretical framework proposed and tested in the cognitive domain by Lemaire and Siegler (1995). In this perspective, a strategy is defined as "a procedure or a set of procedures for achieving a higher level goal or task" (Lemaire \& Reder, 1999, p. 365). In the context of aiming tasks, strategies can be distinguished on the basis of the occurrence of submovements (i.e., no submovements, Type 1,2 , and 3 submovements). Lemaire and Siegler (1995) distinguished between four strategy dimensions, namely strategy repertoire (i.e., which strategies are used?), strategy distribution (i.e., how often each available strategy is used?), strategy execution (i.e., how quickly and accurately each strategy is applied?), and strategy selection (i.e., how do people choose among available strategies on each item?). The present study aimed at testing the usefulness of this framework to study sensorimotor strategies observed in Fitts' tasks and age-related differences therein.

Previous research on cognitive aging found significant differences between young and older adults in the different strategy dimensions (see Lemaire, 2010, for an overview). Indeed, in a wide variety of cognitive domains, young and older adults tend to use different types (and number) of strategies, to use available strategies with different frequencies, and to have different strategy preferences. Moreover, older adults tend to execute strategies less efficiently (i.e., they tend to be slower and less accurate) and to select strategies more poorly (e.g., they tend to choose the best strategy on each item less often than young adults). Whether such systematic age-related differences in strategic variations can be observed in the sensorimotor domain is still unknown. The present study addressed this issue by investigating age-related differences in strategy repertoire, strategy distribution, and execution while participants accomplish Fitts' aiming task.

\section{Objectives and Hypotheses}

The overarching goal of this study was to further our understanding of processes underlying sensorimotor task performance, and their changes with aging. For instance, it is well-known that older adults are slower and more influenced by task difficulty than young adults in Fitts' tasks. The question remains however of whether they use poorer strategies (i.e., that lead to increased movement times) under more difficult conditions or whether they use the same strategies but execute them more slowly than young adults.

The first series of analyses aimed at determining whether the present findings replicate previous findings, a prerequisite condition to analyze strategic aspects in Fitts' task. Thus, we analyzed the efficiency functions (i.e., MTs and DTs as a function of D and W) in young and older participants. Consistent with previous findings, we expected to observe in both age groups a steeper slope for $\mathrm{ID}_{\mathrm{D}}-\mathrm{MT}$ (or $\mathrm{ID}_{\mathrm{D}}-\mathrm{DT}$ ) relation than for $\mathrm{ID}_{\mathrm{W}}-\mathrm{MT}$ (or $\left.\mathrm{ID}_{\mathrm{W}}-\mathrm{DT}\right)$. We also expected to replicate the findings that older 
adults' have longer MTs and larger slopes of efficiency functions (Fitts' law) than young participants. Moreover, we analyzed the distance traveled during the primary submovement for young and older participants. According to previous findings, we expected that amplitudes would be smaller in older adults than in young participants.

We analyzed next age-related differences in strategic variations. Analyses of differences in strategy repertoires (i.e., type and number of strategies) aimed at testing the hypothesis that, in Fitts' task as in many other cognitive tasks, older adults use fewer strategies than young adults. Additionally, we expected that young and older adults should exhibit different strategy preferences and should differ in strategy distribution. Following Dounskaia et al.'s (2005) results, we predicted that young adults should use most frequently strategies with no submovements whereas older adults prefer strategies with submovements. Moreover, for both groups, the selection of strategies should be influenced by task difficulty and the type of manipulation of ID (i.e., W or D). Finally, we tested the hypothesis that condition-related and age-related differences in movement times would depend on the strategy used. To test this hypothesis, we analyzed strategy performance as a function of task difficulty in young and older adults. All in all, our analyses were expected to shed light not only on loci of performance differences between young and older adults, but also to analyze these performance differences so as to inform us on how young and older adults accomplish this Fitts' task.

\section{Method}

\section{Participants}

Eleven older adults (five males, six females, mean age $=78.3$ yo, $S D=6.4$ ), recruited in a leisure and retirement club, and a group of nine young adults (six men, three females, mean age = 25.0 yo, $S D=1.7$ ) students at Aix-Marseille University, participated in the experiment. After a presentation of the experiment, each participant signed an informed written consent, approved by the local ethic committee of Aix-Marseille University, in accordance with the ethical standards laid down in the Declaration of Helsinki. All participants had normal or corrected-to-normal vision, and none of them had a prior experience with the task or the experimental apparatus.

Older participants lived independently and declared to be physically active. They underwent a Standardized Geriatric Assessment supervised by a medical doctor, which evaluated vision, depression, cognition, pain, medication and comorbidity, along with an autonomy assessment of activities of daily living. These assessments attested that older participants did not suffer from pathological cognitive or motor impairments.

\section{Procedure}

Participants were seated on a height-adjustable seat in front of a Wacom graphic tablet (Intuos4 XL) positioned on the tabletop and connected (via a USB port) to a portable PC (Dell, Latitude D420). They had to perform pointing movements with the right arm, by sliding a hand-held nonmarking stylus (Wacom, Generation 2 tip sensor) over the surface of the tablet, from an initial home position toward a target position. Sliding movements were performed in the anterior-posterior direction, with a combination of shoulder flexion and elbow extension. The trunk position was restricted by the chair-back position and the front edge of the table. The starting position, represented as a black square of $0.5 \times 0.5 \mathrm{~cm}$, was always aligned with the center of the target, represented by a black horizontal rectangle $(4 \mathrm{~cm} \times$ various width values). Starting and target positions were printed on a white paper sheet and inserted under the tablet's transparent plastic film cover. The home and target position thus appeared at $14.5 \mathrm{~cm}$ from the left edge of the tablet. Displacements of the stylus on the tablet were recorded using a customized software (ICE) developed at the laboratory (Institute of Movement Sciences, Marseille) at a sampling frequency of $250 \mathrm{~Hz}$.

Before each trial, the stylus was placed on the starting position. Participants were instructed to keep optimal speed-accuracy tradeoff that is "to move as fast as possible from the starting position to the target and to stop on it." Four ID levels, ranging from 3.5 to 6.5 bits by increments of 1 bit were used in this experiment. Task difficulty was obtained via the manipulation of either the size of the target $\left(\mathrm{ID}_{W}\right)$, or its distance from home position $\left(\mathrm{ID}_{D}\right)$. In $W$ manipulation conditions, distance from home position was held constant $(27 \mathrm{~cm})$, and target widths were varied as follows: 4.8 , $2.4,1.2$, or $0.6 \mathrm{~cm}$. In D conditions, target width was held constant $(0.7 \mathrm{~cm})$, and the distances between home position and the center of the target were: $4.0,7.9,15.8$, or $31.7 \mathrm{~cm}$. The order of presentation of $\mathrm{D}$ and $\mathrm{W}$ conditions was counterbalanced across participants and, within each ID manipulation (W or D), the order of presentation of the four ID levels was randomized. Before each ID condition, participants were allowed to complete three (unrecorded) familiarization trials. Afterward, 15 self-paced trials were performed for each of the four conditions. In addition, to help participants adjust the adopted speed-accuracy trade-off, the experimenter provided verbal feedbacks after each condition. If participants erred on 3 or more trials (out of $15)$, they were asked to complete erroneous trials again.

\section{Variables and Data Processing}

The pen-tip raw displacement data were filtered using a secondorder dual pass (no phase-lag) Butterworth filter with a cut-off frequency of $10 \mathrm{~Hz}$. First, second, and third derivatives of displacement (velocity, acceleration, and jerk, respectively) were then computed in MATLAB. Movement onset and offset were determined on the basis of velocity profiles using the optimal algorithm of Teasdale, Bard, Fleury, Young, and Proteau (1993). The critical velocity threshold was obtained by multiplying peak velocity by 0.04 .

First, this procedure allowed us to calculate for each trial, in each condition, the movement time (MT), the deceleration time (DT), and the effective target width (We). The variable movement time, defined as the time between movement onset and offset and the variable deceleration time, defined as the duration following peak velocity, were then used to calculate efficiency functions (EF). Namely, we analyzed the ID-MT and ID-DT relations using simple linear regression models carried out on mean group values. The effective target width (We) was calculated from the standard deviation of movement end points (Mackenzie, 1992). Then, to check whether the prescribed IDs were respected or not, we compared the distributions of movement end points, centered on 
mean movement amplitude and bounded by calculated We, and the prescribed ones, centered on target distance and bounded by target edges (Sleimen-Malkoun et al., 2012). These comparisons yielded no significant statistical difference $(t \mathrm{~s}<1, n s)$.

Second, following Meyer et al. (1988) these data were distinguished into the primary and secondary submovements. The end of the primary submovement was defined as the moment of time when one of the following three events occurred after the velocity reached its peak: (a) the velocity crossed zero, changing from positive to negative, (b) the acceleration crossed zero, changing from negative to positive, or (c) the jerk crossed zero, changing from positive to negative. Examples of the four submovement types during discrete movements are shown in Figure 2.

This procedure allowed us to calculate kinematic variables that were related to the type of the submovement identified. Each submovement has been used to distinguish types of strategies. As a results, four different strategies have been identified which corresponded to different behaviors near the target: (a) the strategy based on velocity zero-crossing constituted the overshoot strategy related to corrections for overshooting; (b) the strategy based on acceleration zero-crossing reflected the undershoot strategy that represented reacceleration toward the target; (c) the progressivedeceleration strategy was determined by zero-crossing of the jerk profile, which corresponded to an increase of the phase of deceleration. (d) If the end of the primary submovement coincided with the movement end, it was considered as the one-shot strategy. We identified which strategy was used on each trial based on these kinematic analyses.

\section{Statistical Analyses}

To check if Fitts' law was respected and if the patterns of performance were comparable to patterns previously reported in the literature, MTs and DTs were first analyzed with an ANOVA involving a 2 (Group) $\times 2$ (Manipulation) $\times 4$ (ID), with repeated measures on the last two factors. Then, ID-MT and ID-DT relations were analyzed using simple linear regression models (EF) carried out on mean group values. The slopes of the different EFs estimated information-processing capacities related to task manipulation in each age group (in bits/s). Student's $t$-statistic was used
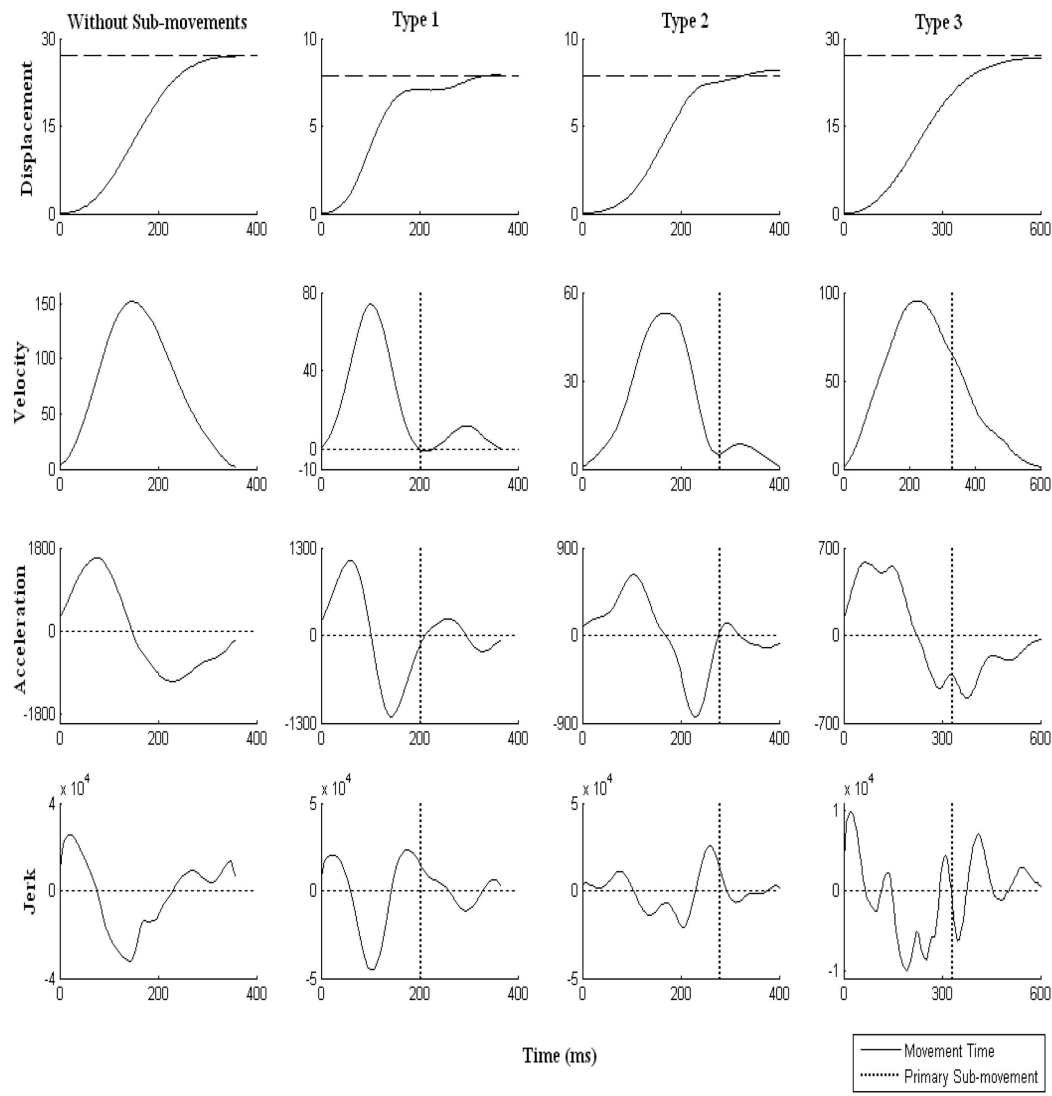

Figure 2. Examples of kinematic profiles extracted from representative trials for one participant during discrete movements without submovements or with Type 1, Type 2, and Type 3 submovements (left to right, respectively). Displacement, velocity, acceleration, and jerk of the stylus were plotted as a function of time and placed vertically (top to bottom). Horizontal dashed lines represent the position of the target. Vertical dotted lines indicate the end of the primary submovement, which corresponded to the end of the total movement when it does not contain secondary submovements. It ended with velocity crossing zero from positive to negative in Type 1 submovements, acceleration crossing zero from negative to positive in Type 2 submovements, and jerk crossing zero from positive to negative in Type 3. 
to compare differences in slopes of regression between groups. We also analyzed the distance traveled during the primary submovement. A 2 (Group) $\times 2$ (Manipulation) $\times 2$ (Difficulty) ANOVA, with repeated measures on the last two factors, was carried out on mean values of this variable.

To examine age-related differences in strategy repertoires, ANOVAs were performed on mean number of strategies used by individuals with a mixed design, 2 (Group) $\times 2$ (Manipulation) $\times$ 2 (Difficulty), with repeated measures on the two last factors. To analyze age-related differences in strategy distributions, a fourway ANOVA (Group $\times$ Manipulation $\times$ Difficulty $\times$ Strategy), with repeated measures on Manipulation (2), Difficulty (2) and Strategy (3), was carried out on mean percentages of use of the three most often used strategies. To analyze age-related differences in strategy execution, a four-way ANOVA (Group $\times$ Manipulation $\times$ Difficulty $\times$ Strategy), with repeated measures on the last three factors was carried out on MTs and DTs. Moreover, we conducted regression analyses for MTs and DTs as a function of IDs, separately for W and D manipulations, in young and older adults while using their preferred strategy.

\section{Results}

Results are presented in four parts. The first analyzes agerelated differences in movement times and deceleration times. The second examines age-related differences in strategy repertoires. The third investigates age-related differences in strategy distributions, and the last looks at age-related differences in strategy execution. Unless otherwise noted, all reported results are significant to at least $p<.05$.

\section{Age-Related Differences in Movement Times (MTs) and Deceleration Times (DTs)}

MTs were significantly larger in older adults than in young adults $\left(768 \mathrm{~ms}\right.$ vs. $404 \mathrm{~ms} ; F(1,18)=21.26, M S \mathrm{e}=245785, n_{p}^{2}=$ $0.54)$ and were larger in $\mathrm{W}$ manipulation compared to $\mathrm{D}$ manipulation $(629 \mathrm{~ms}$ vs. $542 \mathrm{~ms} ; F(1,18)=18.68, M S \mathrm{e}=16035$, $\left.n_{p}^{2}=0.51\right)$. MTs significantly increased with ID scaling (431 $\mathrm{ms}, 532 \mathrm{~ms}, 623 \mathrm{~ms}$, and $757 \mathrm{~ms} ; F(3,54)=47.38, M S \mathrm{e}=$ $\left.16054, n_{p}^{2}=0.72\right)$. This ID effect varied with W/D manipulation, $F(3,54)=7.46, M S e=12254, n_{p}^{2}=0.29$. This interaction resulted from larger increase in MTs as a function of increased IDs for D (333 ms, $471 \mathrm{~ms}, 593 \mathrm{~ms}$, and $772 \mathrm{~ms}$, respectively) than for W manipulation $(528 \mathrm{~ms}, 594 \mathrm{~ms}, 653 \mathrm{~ms}$, and $741 \mathrm{~ms}$, respectively).

DTs were significantly larger in older adults than in young adults $\left(435 \mathrm{~ms}\right.$ vs. $231 \mathrm{~ms} ; F(1,18)=15.40, M S \mathrm{e}=107152, n_{p}^{2}=$ $0.46)$, and were larger in $\mathrm{W}$ manipulation compared to D manipulation $\left(351 \mathrm{~ms}\right.$ vs. $315 \mathrm{~ms} ; F(1,18)=13.05, M S \mathrm{e}=3938, n_{p}^{2}=$ $0.42)$. DTs significantly increased with ID scaling $(230 \mathrm{~ms}, 298$ $\mathrm{ms}, 358 \mathrm{~ms}$, and $446 \mathrm{~ms} ; F(3,54)=61.46, M S \mathrm{e}=5399, n_{p}^{2}=$ $0.77)$. This ID effect varied with $\mathrm{W} / \mathrm{D}$ manipulation, $F(3,54)=$ $3.90, M S \mathrm{e}=2342, n_{p}^{2}=0.18$. This ID effect varied with W/D manipulation, $F(3,54)=3.90, M S \mathrm{e}=2342, n_{p}^{2}=0.18$. This interaction resulted from larger increase in DTs for D (192 ms, 279 $\mathrm{ms}, 345 \mathrm{~ms}$, and $444 \mathrm{~ms}$, respectively) than for $\mathrm{W}$ manipulation (268 ms, $318 \mathrm{~ms}, 372 \mathrm{~ms}$, and $447 \mathrm{~ms}$, respectively).

Efficiency functions resulting from linear fittings of the ID-MT and ID-DT relations in each age group and each manipulation, along with corresponding equations, are displayed in Figures 3 and 4 , respectively. In $W$ manipulation, Fitts' law was found to account for at least $95 \%$ of changes in MTs. Young and older participants' slopes did not differ $(t=0.01, p>.05$, Figure 3 , top panel). This result indicates an additive slowing in older adults. Then, we compared the slopes of DTs for young and older adults. We found a significant difference (48 and 70, respectively; $t=2.14, p<.05$, Figure 4, top panel). This result indicates multiplicative slowing in older adults, with an age-related slowing rate of $44 \%$.

In $\mathrm{D}$ manipulation, the linear fit perfectly accounted for the relation $\mathrm{ID}_{\mathrm{D}}-\mathrm{MTs}\left(R^{2}>99 \%\right.$ for both groups $)$. Older adults' slope was larger than that of young adults (180 and 109, respectively; $t=4.59, p<.05$; Figure 3 , bottom panel). This result showed a multiplicative slowing in older adults, with an age-related slowing rate of $65 \%$. Moreover, comparisons of young and older adult's slopes for DTs differed. Older adults' slope was significantly larger than young adults' slope for DTs (96 and 69, respectively; $t=4.13, p<.05$; Figure 4 , bottom panel). This result indicates a multiplicative slowing in older adults, with an age-related slowing rate of $39 \%$.

To summarize, the present results showed that MTs and DTs followed Fitts' law in both young and older adults. These results were comparable to previously reported data in the literature (e.g., Temprado et al., 2013).

\section{Age-Related Differences in the Amplitude of the Primary Submovement}

Amplitude were significantly shorter in older adults than in young adults $(15.2 \mathrm{~cm}$ vs. $19.1 \mathrm{~cm} ; F(1,18)=39.79 ; M S \mathrm{e}=$ $\left.15.34, n_{p}^{2}=0.74\right)$ and were longer in $\mathrm{W}$ manipulation compared to $\mathrm{D}$ manipulation $(22.3 \mathrm{~cm}$ vs. $11.9 \mathrm{~cm} ; F(1,18)=1630.6 ; M S \mathrm{e}=$
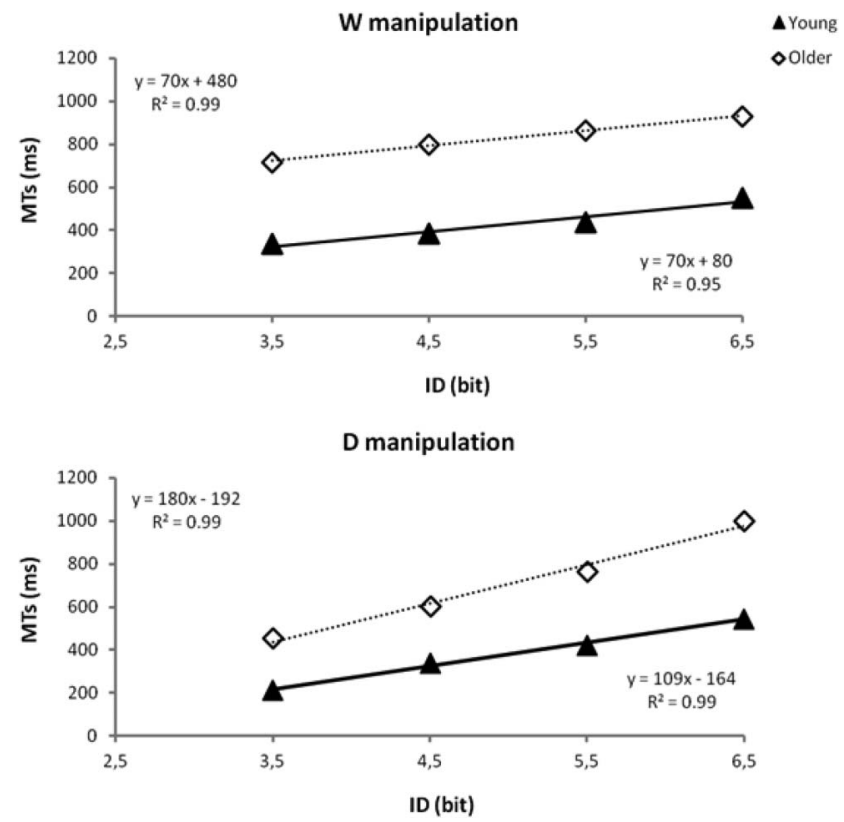

Figure 3. Efficiency functions for movement times (MTs), for W manipulation (top panel) and D manipulation (bottom panel), in young (black triangles) and older (open diamonds) adults. 


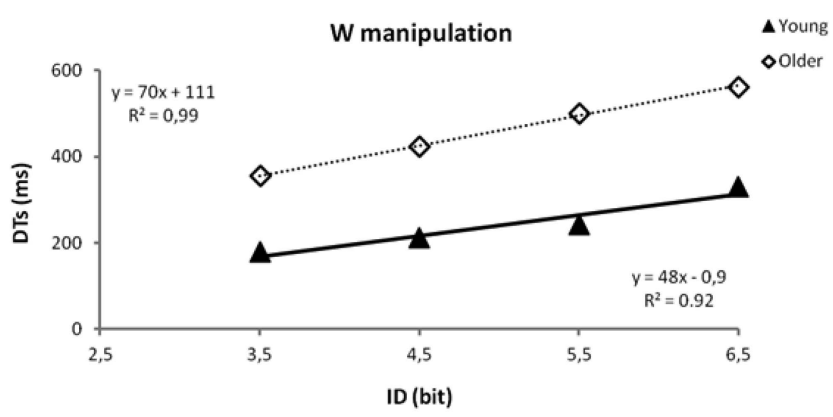

D manipulation

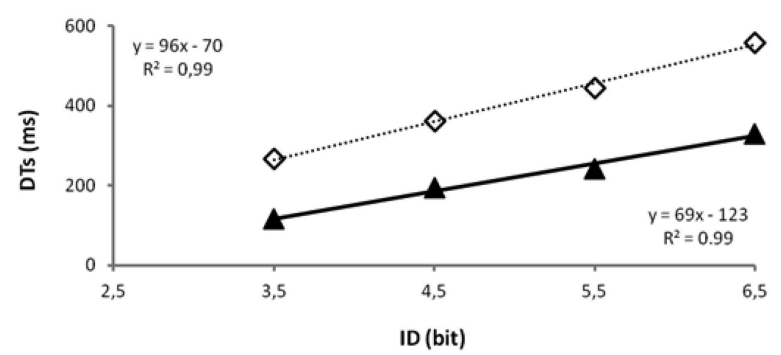

Figure 4. Efficiency functions for deceleration times (DTs), for W manipulation (top panel) and D manipulation (bottom panel), in young (black triangles) and older (open diamonds) adults.

2.63, $\left.n_{p}^{2}=0.99\right)$. Amplitude significantly increased with ID scaling $(13.4 \mathrm{~cm}, 14.7 \mathrm{~cm}, 17.6 \mathrm{~cm}$, and $22.7 \mathrm{~cm} ; F(3,54)=337.65$; $\left.M S \mathrm{e}=1.98, n_{p}^{2}=0.95\right)$. Also, the Group $\times$ Manipulation $\times$ ID interaction became significant $\left(F(1,18)=7.72 ; M S \mathrm{e}=1.58 ; n_{p}^{2}=\right.$ $0.97)$. This interaction resulted from smaller primary submovements in older adults than in young, especially in W manipulation, as compared to D manipulation. Moreover, distances traveled during primary submovements increased as function of ID (see Figure 5) under D manipulation $(4.1 \mathrm{~cm}, 7.6 \mathrm{~cm}, 14.5 \mathrm{~cm}$, and 26.0 $\mathrm{cm}$ for young adults; $3.4 \mathrm{~cm}, 6.4 \mathrm{~cm}, 11.9 \mathrm{~cm}$, and $21.5 \mathrm{~cm}$ for older adults, $F \mathrm{~S}>250.31)$, as compared to $\mathrm{W}$ manipulation (26.0 $\mathrm{cm}, 25.5 \mathrm{~cm}, 25.0 \mathrm{~cm}$, and $24.0 \mathrm{~cm}$ for young adults; $20.2 \mathrm{~cm}, 19.5$ $\mathrm{cm}, 19.0 \mathrm{~cm}$, and $19.3 \mathrm{~cm}$ for older adults, $F \mathrm{~s}<2.45$ ).

In sum, distances traveled during primary submovement varied across trial difficulty, type of manipulations and participants' age.

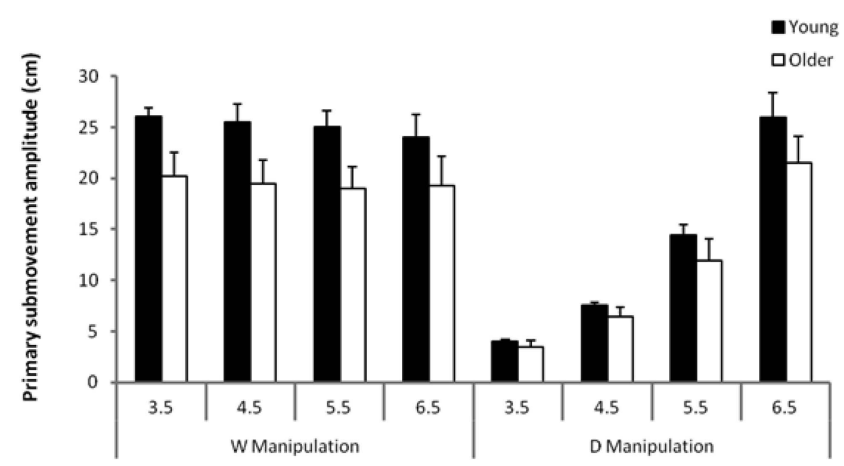

Figure 5. Amplitude of the primary submovement in young and older adults, for the four IDs conditions, in both type of manipulation (D and W). Error bars represent the standard deviation.
More specifically, distances were systematically shorter in older adults, these age-related differences being modulated by trial difficulty only under $D$ manipulation.

\section{Age-Related Differences in Strategy Repertoires}

Examination of kinematic profiles revealed that, at the group level, both young and older participants used the four strategies (i.e., overshoot strategy, undershoot strategy, progressive-deceleration strategy, and one-shot strategy). This set of four strategies accounted for $100 \%$ of trials.

Examining the number of strategies used by individuals revealed strategy variability across individuals (see Table 1).

To simplify the presentation of data and to maximize the number of observations in each condition, we collapsed the four IDs in two different levels (so-called "easy" and "hard") for each ANOVA. Results showed that young individuals used significantly more strategies than older individuals ( 2.3 vs. 2.0 strategies; $\left.F(1,38)=6.41, M S \mathrm{e}=0.56, n_{p}^{2}=0.14\right)$, and that the number of strategies used by individuals did not vary as a function of ID $(F(1$, $38)=2.37, n s)$ or Manipulation $(F<1)$.

In sum, both young and older adults did not use a single strategy to accomplish this Fitts' task. There were at least four different strategies used by participants of both age groups. Also, importantly, the number of strategies used by young and older individuals was not the same, as older adults used on average fewer strategies, suggesting decreasing of strategy repertoire during aging.

\section{Age-Related Differences in Strategy Distributions}

As shown in Table 2, participants used most frequently the progressive-deceleration strategy, followed by the one-shot strategy, and the undershoot strategy. Participants used the overshoot strategy fairly infrequently.

Analyses of strategy use (see means in Table 3) on the three most often used strategies (overshoot strategy, used on only $2 \%$ of trials, was not included) revealed a significant Group $\times$ Strategy interaction $\left(F(2,76)=17.66, M S \mathrm{e}=2871.4 ; n_{p}^{2}=0.32\right)$, showing that strategy distributions varied with participants' age. Indeed, young adults preferred the one-shot strategy, which they used on $50 \%$ of trials. Then, they used the progressive-deceleration strategy $(35 \%)$ and the undershoot strategy $(11 \%)$. Older adults used the progressive-deceleration strategy most often $(51 \%)$, followed by the undershoot strategy (39\%), and they used the one-shot strategy on only $10 \%$ of trials. In other words, compared to young adults, older adults used more frequently the two strategies involving submovements (i.e., undershoot and progressive-deceleration) and less frequently the one-shot strategy (all $F_{\mathrm{S}}>4.66$ comparing young and older adults on each strategy). Moreover, the main

Table 1

Number of Individuals Using 1, 2, 3, or 4 Strategies

\begin{tabular}{llccc}
\hline & \multicolumn{4}{c}{ Number of strategies } \\
\hline Group & 1 & 2 & 3 & 4 \\
Young adults & 0 & 0 & 6 & 3 \\
Older adults & 0 & 4 & 6 & 1 \\
\hline
\end{tabular}


Table 2

Distributions of the Four Strategies Across Participants and Trials

\begin{tabular}{|c|c|c|c|c|c|c|}
\hline \multirow[b]{2}{*}{ Strategy } & \multicolumn{2}{|c|}{$0-33 \%$} & \multicolumn{2}{|c|}{$34-66 \%$} & \multicolumn{2}{|c|}{$67-100 \%$} \\
\hline & Young & Older & Young & Older & Young & Older \\
\hline \multicolumn{7}{|c|}{ Participant-based analyses } \\
\hline Overshoot & 78 & 27 & 0 & 0 & 0 & 0 \\
\hline Undershoot & 100 & 55 & 0 & 25 & 0 & 17 \\
\hline Progressive-deceleration & 33 & 18 & 67 & 73 & 0 & 9 \\
\hline One-shot & 11 & 91 & 67 & 18 & 11 & 0 \\
\hline \multicolumn{7}{|c|}{ Trial-based analyses } \\
\hline Overshoot & 4 & 1 & 0 & 0 & 0 & 0 \\
\hline Undershoot & 11 & 18 & 0 & 43 & 0 & 95 \\
\hline Progressive-deceleration & 14 & 5 & 46 & 59 & 0 & 75 \\
\hline One-shot & 19 & 10 & 49 & 44 & 72 & 0 \\
\hline
\end{tabular}

Note. Each entry in the participant-based analyses represents the percentage of participants using each strategy on less than 34\%, between $34 \%$ and $66 \%$, or more than $66 \%$ of trials. For example, $78 \%$ of young participants used overshoot strategy on less than $34 \%$ of trials. Each entry in the trial-based analyses represents the percentage of trials solved with each strategy by less than $34 \%$ of participants, between $34 \%$ and $66 \%$ of participants, and more than $66 \%$ of participants. For example, $4 \%$ of trials were solved with overshoot strategy by less than $34 \%$ of young adults.

effect of group $\left(F(1,38)=7.23, M S e=11.6, n_{p}^{2}=0.16\right)$ was qualified by a Group $\times$ Manipulation $\times$ Strategy $(F(2,76)=$ $\left.10.68, M S \mathrm{e}=454.5, n_{p}^{2}=0.22\right)$ and a Group $\times$ Difficulty $\times$ Strategy interactions $\left(F(2,76)=9.51, M S \mathrm{e}=595.1, n_{p}^{2}=0.20\right)$.

The Group $\times$ Manipulation $\times$ Strategy interaction came out significant because age-related differences were not the same for each strategy under $\mathrm{D}$ and $\mathrm{W}$ manipulations resulting in different strategy distributions for each age group when $\mathrm{D}$ and W were manipulated. Under the $W$ manipulation, older adults used the progressive-deceleration strategy most often, followed by the undershoot strategy; they used the one-shot strategy least often. In contrast, under the D manipulation, older adults favored the undershoot strategy and then used the progressivedeceleration, and the one-shot strategy. Compared to young adults, older adults used the undershoot and progressivedeceleration strategies more often $(F \mathrm{~s}>7.46)$ and the one-shot strategy less often, $F(1,38)=66.44$ under the $\mathrm{W}$ manipulation.
Under the D manipulation, older adults used the undershoot strategy more often than young adults, $F(1,38)=14.88$, the progressive deceleration equally often $(F<1)$ and the one-shot strategy less often, $F(1,38)=19.31$.

Moreover, the Group $\times$ Difficulty $\times$ Strategy interaction stemmed from the same strategy preferences for easy and high ID in older adults but different strategy preferences for each level of difficulty in young adults. Indeed, older adults used the progressive-deceleration strategy most often and the one-shot strategy least often, with the undershoot strategy in-between for both easy and high IDs. For low ID, young adults used the one-shot strategy most often, followed by the progressive-deceleration; they used the undershoot strategy least often. In contrast, for high ID, young adults favored the progressive-deceleration strategy most often and then used the undershoot strategy and the one-shot strategy. Compared to young adults, older adults used the undershoot and progressive-deceleration strategies more often $(F \mathrm{~S}>14.29)$ and the one-shot strategy less often, $F(1,38)=51.36$ under the low IDs. In the high ID condition, older adults used the undershoot strategy more often than young adults, $F(1,38)=7.72$, the progressive deceleration equally often $(F<1)$, and the oneshot strategy less often, $F(1,38)=25.42$.

Finally, the Manipulation $\times$ ID $\times$ Strategy interaction was significant, $F(2,76)=9.13, p<.001)$, as difficulty-related differences in each strategy use was modulated by the $\mathrm{D} / \mathrm{W}$ manipulations. Under both the $\mathrm{W}$ and $\mathrm{D}$ manipulations, participants used the undershoot and progressive-deceleration strategies more often in the high-difficulty condition than in the low-difficulty condition $(F \mathrm{~s}>2.37)$, although the high-low differences were smaller under the D manipulations. Participants used the one-shot strategy more often in the low-ID than under the high-ID condition for both $\mathrm{W}$ and $\mathrm{D}$ manipulation $(F \mathrm{~s}<40.27)$.

In sum, strategy use varied across trial difficulty, type of manipulations and participants' age. In general, young adults predominantly used one-shot strategy whereas older adults predominantly used progressive-deceleration strategy, and these age-related differences were modulated by trial difficulty under each $\mathrm{W}$ and $\mathrm{D}$ manipulation.

\section{Age-Related Differences in Strategy Execution}

As can been seen in Table 4, analyses of MTs revealed that young adults were faster than older adults (436 ms vs. $696 \mathrm{~ms} ; F(1$,

Table 3

Percentages of Use of One-Shot, Undershoot, and Progressive-Deceleration Strategies in Each Group of Participants and for Each Manipulation Type and Trial Difficulty

\begin{tabular}{|c|c|c|c|c|c|c|}
\hline \multirow[b]{2}{*}{ Trial difficulty } & \multicolumn{3}{|c|}{ W manipulation } & \multicolumn{3}{|c|}{ D manipulation } \\
\hline & One-shot & Undershoot & Progressive-deceleration & One-shot & Undershoot & Progressive-deceleration \\
\hline \multicolumn{7}{|c|}{ Young adults } \\
\hline Low ID & 76 & 2 & 22 & 61 & 17 & 14 \\
\hline High ID & 37 & 14 & 47 & 27 & 13 & 58 \\
\hline Means & 56 & 8 & 35 & 44 & 15 & 36 \\
\hline \multicolumn{7}{|c|}{ Older adults } \\
\hline Low ID & 14 & 25 & 61 & 18 & 53 & 28 \\
\hline High ID & 2 & 34 & 63 & 7 & 42 & 50 \\
\hline Means & 8 & 29 & 62 & 13 & 48 & 39 \\
\hline
\end{tabular}


Table 4

Mean Movement Times (MTs) and Deceleration Times (DTs) in ms in Young and Older Adults While Using the One-Shot, Undershoot, or Progressive-Deceleration Strategy

\begin{tabular}{|c|c|c|c|c|}
\hline Group & One-shot & Undershoot & $\begin{array}{l}\text { Progressive- } \\
\text { deceleration }\end{array}$ & Means \\
\hline \multicolumn{5}{|c|}{ Movement times (MTs) } \\
\hline Young adults & 336 & 510 & 463 & 436 \\
\hline Older adults & 507 & 822 & 758 & 696 \\
\hline Means & 422 & 666 & 610 & 567 \\
\hline Older-Young & 171 & 312 & 295 & 291 \\
\hline \multicolumn{5}{|c|}{ Deceleration times (DTs) } \\
\hline Young adults & 217 & 331 & 306 & 285 \\
\hline Older adults & 227 & 491 & 413 & 377 \\
\hline Means & 222 & 411 & 360 & 331 \\
\hline Older-Young & 10 & 160 & 107 & 92 \\
\hline
\end{tabular}

18) $\left.=24.10, M S \mathrm{e}=41482, n_{p}^{2}=0.57\right)$. A main effect of strategy was found $\left(F(2,36)=28.50, M S \mathrm{e}=11374, n_{p}^{2}=0.61\right)$. Pairwise comparisons revealed that participants were faster with the oneshot strategy than with the progressive-deceleration strategy, $F(1$, $18)=40.26$, or than with the undershoot strategy, $F(1,18)=$ 31.93. Also, participants were faster with the progressivedeceleration strategy than with the undershoot strategy, $F(1,18)=$ 4.44. The Group $\times$ Strategy interaction was marginally significant $\left(F(2,36)=2.57, p=.09, M S \mathrm{e}=11374, n_{p}^{2}=0.13\right)$. Although young adults were faster than older adults whatever strategies participants used $(F \mathrm{~s}>12.15)$, the old-young differences were the largest with the undershoot strategy $(312 \mathrm{~ms})$ and with the progressive-deceleration strategy $(295 \mathrm{~ms})$; they were the smallest with the one-shot strategy $(171 \mathrm{~ms})$.

Analyses of DTs revealed that young adults spent less time decelerating than older adults $(285 \mathrm{~ms}$ vs. $377 \mathrm{~ms} ; F(1,18)=9.51$, $\left.M S \mathrm{e}=13463, n_{p}^{2}=0.35\right)$. A main effect of strategy was found $\left(F(2,36)=41.07, M S \mathrm{e}=4617, n_{p}^{2}=0.70\right)$. Pairwise comparisons revealed that participants spent less time decelerating during execution of the one-shot strategy than when executing the progressive-deceleration strategy, $F(1,18)=41.15$, or than with the undershoot strategy, $F(1,18)=49.82$. Also, participants spent less time decelerating with the progressive-deceleration strategy than with the undershoot strategy, $F(1,18)=9.68$. The Group $\times$ Strategy interaction was significant, $F(2,36)=6.27$, $M S \mathrm{e}=4617, n_{p}^{2}=0.26$. Contrasts revealed that young adults spent less time decelerating than older adults while using the undershoot strategy, $F(1,18)=9.32$ and with the progressive-deceleration strategy, $F(1,18)=7.47$, but not when they used the one-shot strategy $(F<1)$. Indeed, the old-young differences were larger with the undershoot strategy $(160 \mathrm{~ms})$ than with the progressivedeceleration strategy $(107 \mathrm{~ms})$, and were close to $0(10 \mathrm{~ms})$ with the one-shot strategy.

In order to gain a deeper understanding of how age-related differences in strategy execution are modulated by variations of task difficulty, the next set of analyses focused on the most often used strategies by each age group (i.e., the one-shot strategy in young adults and the progressive-deceleration strategy in older adults). To this end, we ran regression analyses predicting MTs and DTs as a function of IDs, separately for W and D manip- ulations (see Figure 6 and 7), in young and older adults while using one-shot and progressive-deceleration strategies.

First, regarding W manipulation, results showed that slopes for young and older adults' MTs were comparable (42 and 39, respectively; $t<1$ ) but young and older adults' slopes of DTs differed significantly (27 and 44, respectively; $t=2.17$ ). Ratio between DTs' slopes showed an age-related slowing rate of $60 \%$. Second, concerning D manipulation, results showed that slopes for young and older adults' MTs were different (79 and 109, respectively; $t=$ 2.09). Ratio between MTs' slopes showed a slowing rate of $40 \%$. Moreover, comparisons of slopes for young and older adults' DTs showed a significant difference (49 and 71 , respectively; $t=2.02$ ). Ratio between DTs' slopes indicated a slowing rate of $45 \%$.

To summarize, the different strategies that young and older adults used to accomplished the present Fitts' task differed in relative efficacy. Moreover, although the hierarchy of relative strategy difficulty was the same in young and older adults (i.e., the one-shot strategy was faster than the progressive-deceleration strategy that was faster than the undershoot strategy), age-related differences tended to be larger for the more difficult strategy (i.e., undershoot strategy) than for the easier strategy (i.e., one-shot strategy). Effects of trial difficulty on strategy execution were enhanced in older adults, even when we compared movement times for the most favorite strategy in each age group.

\section{General Discussion}

The objective of the present study was to contribute to further our understanding of cognitive processes underlying sensorimotor behaviors and age-related differences in these processes. More specifically, we examined how age-related differences in strategic
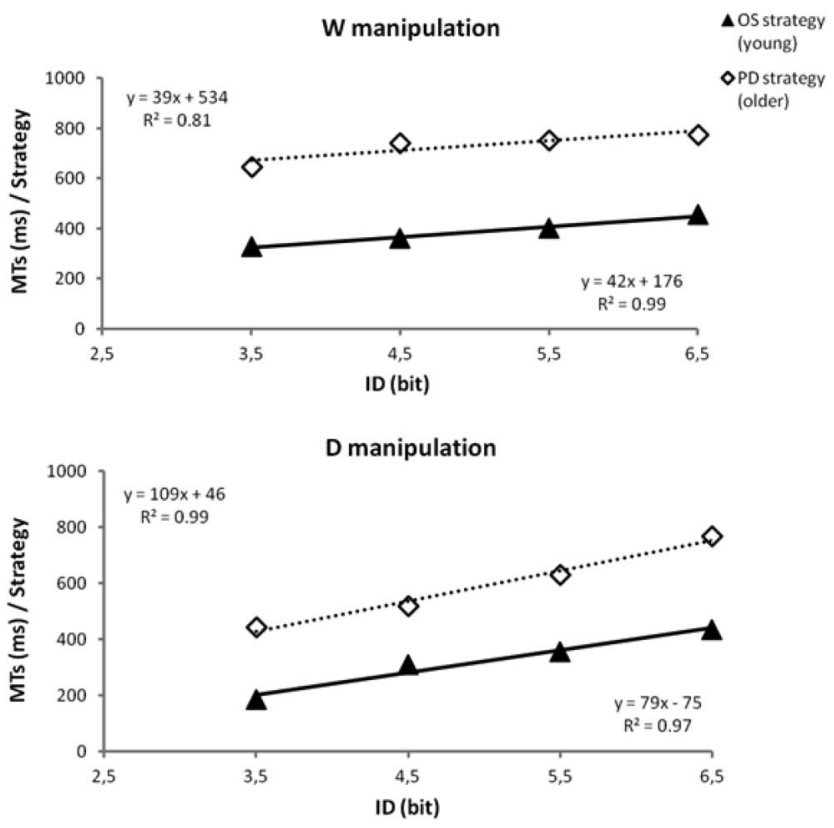

Figure 6. Efficiency functions for movement times (MTs) associated with each group's favorite strategy (i.e., progressive-deceleration strategy in older adults and one-shot strategy in young adults) under W and D manipulations. 

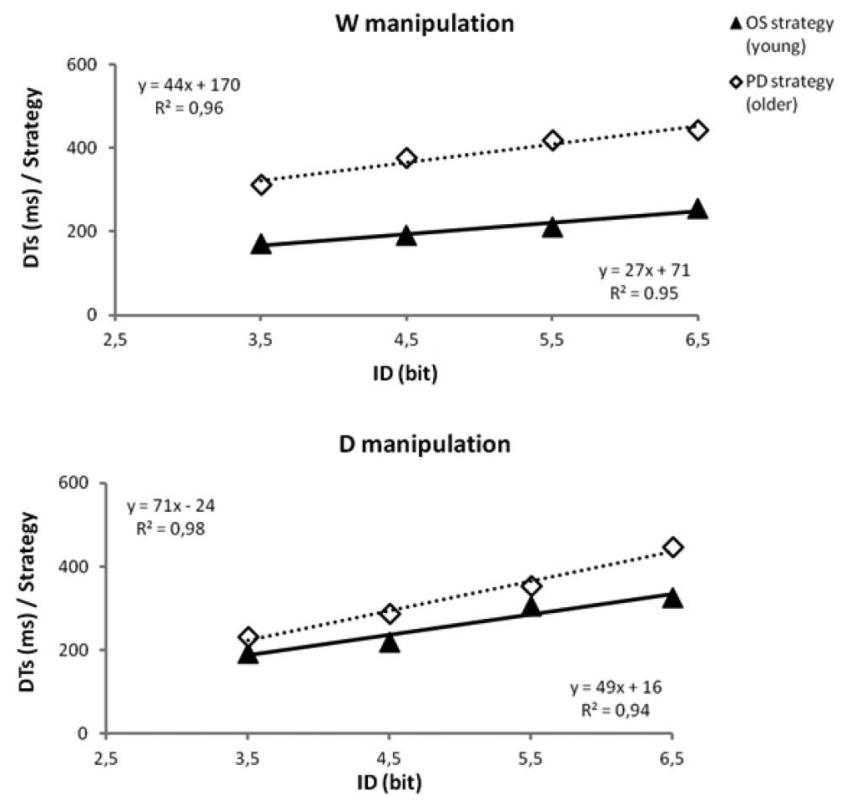

Figure 7. Efficiency functions for deceleration times (DTs) associated each group's favorite strategy (i.e., progressive-deceleration strategy in older adults and one-shot strategy in young adults) under $\mathrm{W}$ and D manipulations.

variations characterized sensorimotor behaviors during unimanual discrete Fitts' task. The most original feature of the present study is a conceptual approach distinguishing among several strategy dimensions, coupled with assessment of strategies used by young and older adults on each trial under varying conditions of difficulty. In this respect, it is noticeable that the strategy perspective adapted here has not been unanimously accepted by researchers of the motor control community, an issue that we will discuss when relating the present findings with previous works. Our results replicated previous general findings regarding participants' performance in Fitts' tasks as well as most robust age-related differences (older participants were slower than younger participants for both $\mathrm{D}$ and $\mathrm{W}$ manipulations; and steeper slopes of efficiency functions were observed for $\mathrm{D}$ manipulation as compared to $W$ manipulation). Most originally, our results showed age-related changes in sensorimotor strategies, offering a much more precise depiction of cognitive changes than is currently obtained. In this section, we discuss the main results of this study, along with their general implications on understanding the processes underlying sensorimotor performance and age-related differences in sensorimotor behaviors.

Beyond replicating quantitative findings concerning age-related motor slowing and decrease in information-processing rates in a Fitts' aiming task, we applied the conceptual framework previously introduced in the cognitive domain by Lemaire and Siegler (1995; see Lemaire, 2010), to gain further insights on how aging affects strategic aspects of sensorimotor behaviors in rapid aiming. Specifically, our results shed lights on how young and older adults perform this task (i.e., which processes are implicated) and whether the differences in task constraints management (i.e., how participant plan and execute the task) could explain, or at least are associated with, the observed age-related cognitive-motor slowing.

\section{Age-Related Differences in Strategy Repertoires}

Concerning how young and older participants performed discrete Fitts' task, we found that there were at least four different strategies distinguished on basis and type of submovements that were observed in the kinematic profiles. Of the four available strategies, when all IDs and both manipulations were considered together, both age groups favored the progressive-deceleration strategy. More interestingly, the present data revealed that overall, older individuals used a smaller number of strategies than young individuals. Moreover, we found that the decreasing number of strategies with age depended on ID level and the type of manipulation. Specifically, older individuals tended to use a smaller number of strategies in the higher ID level under $W$ manipulation, and in the lower ID level under D manipulation. Knowing that, compared to $\mathrm{W}$ manipulation, D manipulation globally imposes greater processing demands on the cognitive-motor system, and that this difference is enhanced during aging (Sleimen-Malkoun et al., 2012; Temprado et al., 2013), these results suggest that when processing resources are reduced, older adults decrease the number of strategies maintained active in working memory. Choice processes may thereby be less demanding in older adults who are known to have fewer available processing resources. Indeed, choosing among fewer strategies is known to be less demanding than choosing among more strategies on each trial, especially in older adults (e.g., Ardiale, Hodzik, \& Lemaire, 2012). Although our study was not designed to directly test this prediction, it could be argued that in sensorimotor tasks, the reduction in strategy repertoire might help older adults' to maintain a high level of sensorimotor performance. This hypothesis could be tested in future studies by comparing age-related differences in participants' performance when the number of allowed strategies to be used is manipulated. If age-related decrease in the number of strategies helps older adults to obtain better performance, we should observe smaller age differences when participants are tested under conditions where they can use fewer versus more strategies. Furthermore, the decreasing number of strategies with age could also be interpreted as the reflection of processes of dedifferentiation (see Sleimen-Malkoun, Temprado, \& Hong, 2014, for theoretical development).

To our knowledge, the present study is the first to report age-related reduction in strategy repertoire in a Fitts' task. In this respect, our findings are consistent with those observed by previous studies in a variety of cognitive domains like arithmetic (e.g., Hodzik \& Lemaire, 2011; Lemaire \& Arnaud, 2008), reading (e.g., Shake, Noh, \& Stine-Morrow, 2009; Stine-Morrow, Miller, \& Hertzog, 2006), selective attention (e.g., Folk \& Hoyer, 1992), or episodic memory (e.g., Kuhlmann \& Touron, 2012), and decision making (e.g., Mata \& Nunes, 2010). Therefore, it strongly suggests that age-related decrease in strategy repertoire is a common principle to aging in cognitive and sensorimotor domains. Indeed, age-related decrease in strategy repertoires may be the result of common factors (e.g., decreased processing resources with increasing age) or may be the result of specific factors that happen to yield parallel effects when participants have to accomplish both cognitive and sensorimotor tasks. For instance, it is possible that age-related decrease in working memory resources may be responsible for reducing the strategic repertoire during aging. It would be interesting to determine whether the number of sensorimotor strat- 
egies decreases in dual-task condition. Indeed, if working memory is at stake, we should observe a decreased number of strategies in young adults when tested under dual-task (compared to singletask) condition, and an even larger decrease in older adults.

\section{Age-related Differences in Strategy Distributions}

It is also important to note that different strategy distributions in young and older adults were found, and these age-related differences were modulated by task difficulty under $\mathrm{W}$ and $\mathrm{D}$ manipulations. Consistent with Ketcham et al. (2002) (see also Pratt, Chasteen, \& Abrams, 1994; Van Halewyck et al., 2014), we found that young adults predominantly used strategy without submovements (i.e., the one-shot strategy) whereas older adults more frequently used strategies involving submovements (i.e., the undershoot and progressive-deceleration strategies) during movement execution. This is consistent with the observed systematic decrease of primary submovements' amplitude in older adults (reported also in Ketcham et al., 2002; Pratt et al., 1994; Worringham, 1991; however, see Welsh, Higgins, \& Elliott, 2007 for a different result). It suggests that older adults favored a strategy consisting of relatively shorter primary submovements relying thus on the visually guided deceleration phase, even at the expense of slowing down movement execution. Here, it is important to note that compared to young adults, the duration of the primary submovement remains much longer in older adults. These findings are consistent with Ketcham et al.'s (2002) proposal that older adults are much less able than young adults to calibrate the initial impulse of movement, due to alterations of neuromuscular factors.

The present study went a step further than previous studies which aggregated the different movements involving submovements (Ketcham et al., 2002; Meyer et al., 1988). Here, we explicitly and systematically linked the different submovement types (i.e., no submovements, Type 1, 2, 3 submovements) to distinct strategies (i.e., one-shot, overshoot, undershoot, and progressive-deceleration strategies, respectively). We found that the occurrence of these strategies was influenced by age, task difficulty (ID level), and by the type of ID manipulations ( $D$ or $W$ ). Submovements had commonly been considered as the signature of corrective processes, based on sensory feedback processing, ensuring the accuracy of movement endpoint. Dounskaia and collaborators (2005; Wisleder \& Dounskaia, 2007; Fradet et al., 2008) challenged however this traditional interpretation. They considered that aiming movement actually include different subtasks, namely achieving accuracy (accuracy subtask) and dissipating mechanical energy to stop the movement (motion termination subtask). Consequently, they assumed that specific kinematic organization of movements should be related to these subtasks, with Type 3 submovements associated with accuracy control, and Type 1 as well as Type 2 submovements associated with motion termination (Dounskaia et al., 2005). Importantly, they concluded that the gross submovements were emerging by-products of mechanical constraints, rather than cognitive processes strategically used to improve performance. In another study, Wisleder and Dounskaia (2007) challenged the interpretation of fine submovements (Type 3 ) as corrections performed voluntarily to improve pointing accuracy, and they proposed the possibility that these submovements could be an inherent property of low-speed movements. However, their conclusion can be challenged, since error rates were not controlled for in their study. Indeed, when participants performed cyclic movements at $2.0 \mathrm{~Hz}$, the accuracy constraint was not respected, as shown by the variable error (calculated as the bivariate planar error, 5.0 vs. $6.3 \mathrm{~mm}$ for 1 and $2.5 \mathrm{~Hz}$ conditions, respectively). The results of the present study, in which error rates were controlled, afford a different account. They showed that, in young adults, mechanical constraints were not what determined strategy use since the overshoot and undershoot strategies (corresponding to gross submovements) were rarely employed. Conversely, task constraints seem to be a more determinant factor. Indeed, the progressive-deceleration strategy (corresponding to fine submovements) was more often used when the accuracy constraint was important while the one-shot strategy was the most frequent when the accuracy constraint was low.

More specifically, young adults presented a similar pattern of strategy use across D and $\mathrm{W}$ manipulations, while older adults were differentially influenced by D and W manipulations. Indeed, young adults more often used the one-shot strategy, followed by the progressive-deceleration strategy, and the undershoot strategy. These results suggest that young adults were able to implement this strategy, which does not include corrective submovements, whatever the constraints of the task (i.e., target size or movement distance). One can hypothesize that this choice reflected the emphasis on response speed in young adults and, likely, less dependence on visual control of movement execution. Decrease in target width (W manipulation) led older adults to predominantly adopt the progressive-deceleration strategies, while increasing movement distance (i.e., under D manipulation) led them to adopt the undershoot and progressive-decelerations strategies with equivalent frequencies. However, it is important to note that when the difficulty of the task was manipulated via target distance, a stronger accuracy constraint was imposed for target width $(0.7 \mathrm{~cm})$. Thus, it seems that in older adults, changing ID level through decreasing target width is less constraining on strategy use than changing difficulty through movement distance manipulation. Indeed, data suggest that older adults tended to focus on response accuracy and are more able to choose the strategy allowing them to avoid missing the target, especially under W manipulation, where they mostly used the progressive-deceleration strategy. Conversely, under D manipulation, results showed that they used equally often undershoot and progressive-deceleration strategies, thereby reflecting uncertainty in movement organization strategy choices. Moreover, we saw that it was possible to generate the same ID by manipulating target width or target distance. However, the sensorimotor processes involved in movement execution are differently loaded. Thus, one could predict that for a small target $(0.7 \mathrm{~cm})$, participants tend to mainly use the same strategy that was used in $\mathrm{W}$ manipulation (i.e., the progressive-deceleration strategy). In addition, under $\mathrm{D}$ manipulation, as older adults are also deficient on the impulse phase, it is possible that a second strategy would appear (i.e., the undershoot strategy) and may be related to the first part of the movement. This hypothesis could be tested by correlating the properties of the first part of the movement (i.e., amplitude, duration or variability) and the incident frequencies of strategies.

Furthermore, changes in ID levels also revealed different strategy distributions. Indeed, young adults had different strategy distributions across low and high ID levels, while older adults presented the same patterns of strategy use. Specifically, increasing 
ID level, led young adults to switch from predominant use of the one-shot strategy to the progressive-deceleration strategy. The frequency of use of the undershoot strategy was slightly affected. It seems that, when the difficulty of the task increase, the best strategy to reach the target is the progressive-deceleration strategy. Older adults in contrast used undershoot and progressivedeceleration strategies equally often and the one-shot strategy least often, under both low and high IDs. These results suggest that older adults tended to be less flexible in the use of different strategies, thereby making them less adaptive than young adults when faced with increasing task difficulty. In addition, by predominantly adopting undershoot strategies, older adults avoided movement reversals that involve greater time and energy costs. Whether this was a goal that participants intentionally pursued cannot be unambiguously determined here and deserves further investigation. In this perspective, explicit changes in task instructions given to participants (e.g., emphasis on speed or accuracy, focus of attention onto specific aspects of the movement) could modulate aging effects on strategic variations. As in many cognitive domains (see Lemaire, 2010, for an overview), aging effects have been found to interact with several task parameters. This possibility would be important to test in sensorimotor strategies.

\section{Age-Related Differences in Strategy Execution}

An additional interesting set of results in the present data was that the different strategies that young and older adults used to accomplish the present Fitts' task differed in relative efficacy. First, we found that the hierarchy of relative strategy difficulty was the same in young and older adults. Indeed, the one-shot strategy was faster than the progressive-deceleration strategy that was faster than the undershoot strategy. Here, we describe a strategy to be more or less difficult on the basis of MT (i.e., the longer the MT, the more difficult the strategy). Moreover, we observed that age-related differences tended to be larger for the more difficult strategy (i.e., undershoot strategy) than for the easier strategy (i.e., one-shot strategy). Whether poorer chronometric performance of older adults resulted from strategy selection or strategy execution remains to be determined. One could hypothesize in this respect that older adults, besides being slower in execution, could be also slower because they use more frequently time-consuming strategies (i.e., undershoot or progressive-deceleration strategy), relative to young adults. This would decrease the demands in cognitive resources to select among multiple strategies on each trial. In this vein, it would be interesting to determine how parameters of Fitts' law for each MT and DT measure change (or do not change) when young and older adults use each strategy. This was impossible to assess here given insufficient and unbalanced number of observations for each Strategy $\times$ Difficulty, as a result of strategy selection. Moreover, it would be interesting to determine whether the Age $\times$ Strategy interaction found here would be similarly found, had all participants used all available strategies with equal. Future studies, using the choice/no choice method proposed by Siegler and Lemaire (1997) and adapted to Fitts' task should enable to disentangle contributions of strategy selection and strategy execution to age-related differences in strategy performance, and determine whether Fitts' law differ or not for each strategy in each age group.
In addition, age-related differences in strategy execution also depended on variations of task difficulty or task manipulations. Indeed, in the present study, given free strategy selection leading to small and highly unequal numbers of observations between strategies across difficulty condition, the time taken to execute each strategy was averaged across ID levels and both manipulations. Previous studies showed that both manipulations and IDs resulted in different loadings of control mechanisms (impulse and correction) (Ketcham et al., 2002; Rey-Robert et al., 2012; Teeken et al., 1996; Temprado et al., 2013). For instance, using Brinley plots, Temprado et al. (2013) have shown that young and older adults' MTs were similarly affected by $W$ manipulation (slope = 1 ), but those of older adults were more affected by D manipulation (slope $=1.3$ ). Thereby, it is possible that given their capacities (muscular, cognitive, or information processing), participants use different strategies to comply with the speed-accuracy trade-off. More studies with more observations in each ID for each W/D manipulation are thus necessary to compare age-related differences in strategy execution for Fitts' discrete aiming task and to further understand how strategic aspects for sensorimotor performance contribute to age and condition-related differences.

\section{Conclusion and Perspectives}

All in all, the present study documented, for the first time to our knowledge, age-related similarities and differences in strategic variations in the sensorimotor domain as seen in a Fitts' discrete aiming task. Our findings demonstrated the existence of significant age-related differences in strategy repertoire, strategy distribution, and strategy execution. Interestingly, the strategic variations observed in the present study closely paralleled those previously observed in many cognitive domains (see Lemaire, 2010, for an overview). Thus, strategic variations in cognitive and motor domains seem to follow general and common principles. Beyond the confirmation that the study of strategic variations is of primary importance to better understanding changes in human performance during aging, these findings point to the commonalities between cognitive and motor domains, even with respect to strategic aspects. The origins of these commonalities certainly deserve further investigations. A plausible hypothesis is that cognitive resources are highly involved in Fitts' task - and more generally in most of sensorimotor tasks - (for confirming evidence, see SleimenMalkoun et al., 2013; Rey-Robert et al., 2011; Temprado et al., 2013) like in cognitive tasks so that strategic variations follow the same principles in both sensorimotor and cognitive tasks.

\section{References}

Ardiale, E., Hodzik, S., \& Lemaire, P. (2012). Aging and strategy switch costs: A study in arithmetic problem solving. L'Année Psychologique, 112, 345-360. http://dx.doi.org/10.4074/S0003503312003028

Bennett, S. J., Elliott, D., \& Rodacki, A. (2012). Movement strategies in vertical aiming of older adults. Experimental Brain Research, 216, 445-455. http://dx.doi.org/10.1007/s00221-011-2947-x

Dounskaia, N., Wisleder, D., \& Johnson, T. (2005). Influence of biomechanical factors on substructure of pointing movements. Experimental Brain Research, 164, 505-516. http://dx.doi.org/10.1007/s00221-0052271-4

Elliott, D., Hansen, S., \& Grierson, L. E. M. (2009). Optimising speed and energy expenditure in accurate visually directed upper limb movements. Ergonomics, 52, 438-447. http://dx.doi.org/10.1080/00140130802707717 
Elliott, D., Hansen, S., Grierson, L. E. M., Lyons, J., Bennett, S. J., \& Hayes, S. J. (2010). Goal-directed aiming: Two components but multiple processes. Psychological Bulletin, 136, 1023-1044. http://dx.doi.org/ 10.1037/a0020958

Elliott, D., Hansen, S., Mendoza, J., \& Tremblay, L. (2004). Learning to optimize speed, accuracy, and energy expenditure: A framework for understanding speed-accuracy relations in goal-directed aiming. Journal of Motor Behavior, 36, 339-351. http://dx.doi.org/10.3200/JMBR.36.3 .339-351

Elliott, D., Helsen, W. F., \& Chua, R. (2001). A century later: Woodworth's (1899) two-component model of goal-directed aiming. Psychological Bulletin, 127, 342-357. http://dx.doi.org/10.1037/0033-2909.127 .3 .342

Falkenstein, M., Yordanova, J., \& Kolev, V. (2006). Effects of aging on slowing of motor-response generation. International Journal of Psychophysiology, 59, 22-29. http://dx.doi.org/10.1016/j.ijpsycho.2005.08.004

Fitts, P. M. (1954). The information capacity of the human motor system in controlling the amplitude of movement. Journal of Experimental Psychology, 47, 381-391. http://dx.doi.org/10.1037/h0055392

Fitts, P. M., \& Peterson, J. R. (1964). Information capacity of discrete motor responses. Journal of Experimental Psychology, 67, 103-112. http://dx.doi.org/10.1037/h0045689

Folk, C. L., \& Hoyer, W. J. (1992). Aging and shifts of visual spatial attention. Psychology and Aging, 7, 453-465. http://dx.doi.org/10.1037/ 0882-7974.7.3.453

Fradet, L., Lee, G., \& Dounskaia, N. (2008). Origins of submovements in movements of elderly adults. Journal of Neuroengineering and Rehabilitation, 5, 28. http://dx.doi.org/10.1186/1743-0003-5-28

Gregory, R. L. (1957). Neurological noise as a factor in aging. Proceedings of the Fourth International Congress of the International Association on Gerontology (Vol. 1, pp. 314-324). Merano, Italy: Tipographica Tito Mattioli.

Haaland, K. Y., Harrington, D. L., \& Grice, J. W. (1993). Effects of aging on planning and implementing arm movements. Psychology and Aging, 8, 617-632. http://dx.doi.org/10.1037/0882-7974.8.4.617

Heuninckx, S., Wenderoth, N., Debaere, F., Peeters, R., \& Swinnen, S. P. (2005). Neural basis of aging: The penetration of cognition into action control. The Journal of Neuroscience, 25, 6787-6796. http://dx.doi.org/ 10.1523/JNEUROSCI.1263-05.2005

Hodzik, S., \& Lemaire, P. (2011). Inhibition and shifting capacities mediate adults' age-related differences in strategy selection and repertoire. Acta Psychologica, 137, 335-344. http://dx.doi.org/10.1016/j.actpsy .2011 .04 .002

Horak, F. B., \& Nashner, L. M. (1986). Central programming of postural movements: Adaptation to altered support-surface configurations. Journal of Neurophysiology, 55, 1369-1381.

Huys, R., Fernandez, L., Bootsma, R. J., \& Jirsa, V. K. (2010). Fitts' law is not continuous in reciprocal aiming. Proceedings. Biological Sciences/ The Royal Society, 277, 1179-1184. http://dx.doi.org/10.1098/rspb .2009 .1954

Ketcham, C. J., Seidler, R. D., Van Gemmert, A. W. A., \& Stelmach, G. E. (2002). Age-related kinematic differences as influenced by task difficulty, target size, and movement amplitude. The Journals of Gerontology. Series B, Psychological Sciences and Social Sciences, 57, P54P64. http://dx.doi.org/10.1093/geronb/57.1.P54

Kolev, V., Falkenstein, M., \& Yordanova, J. (2006). Motor-response generation as a source of aging-related behavioural slowing in choicereaction tasks. Neurobiology of Aging, 27, 1719-1730. http://dx.doi.org/ 10.1016/j.neurobiolaging.2005.09.027

Kuhlmann, B. G., \& Touron, D. R. (2012). Mediator-based encoding strategies in source monitoring in young and older adults. Journal of Experimental Psychology: Learning, Memory, and Cognition, 38, 13521364. http://dx.doi.org/10.1037/a0027863
Lemaire, P. (2010). Cognitive strategy variations during aging. Current Directions in Psychological Science, 19, 363-369. http://dx.doi.org/ 10.1177/0963721410390354

Lemaire, P., \& Arnaud, L. (2008). Young and older adults' strategies in complex arithmetic. The American Journal of Psychology, 121, 1-16. http://dx.doi.org/10.2307/20445440

Lemaire, P., \& Reder, L. (1999). What effects strategy selection in arithmetic? The example of parity and five effects on product verification. Memory \& Cognition, 27, 364-382. http://dx.doi.org/10.3758/ BF03211420

Lemaire, P., \& Siegler, R. S. (1995). Four aspects of strategic change: Contributions to children's learning of multiplication. Journal of Experimental Psychology: General, 124, 83-97. http://dx.doi.org/10.1037/ 0096-3445.124.1.83

Li, K. Z. H., \& Lindenberger, U. (2002). Relations between aging sensory/ sensorimotor and cognitive functions. Neuroscience and Biobehavioral Reviews, 26, 777-783. http://dx.doi.org/10.1016/S0149-7634(02) 00073-8

Li, S.-C., \& Dinse, H. R. (2002). Aging of the brain, sensorimotor, and cognitive processes. Neuroscience and Biobehavioral Reviews, 26, 729 732. http://dx.doi.org/10.1016/S0149-7634(02)00059-3

Light, K. E., \& Spirduso, W. W. (1990). Effects of adult aging on the movement complexity factor of response programming. The Journal of Gerontology, 45, P107-P109. http://dx.doi.org/10.1093/geronj/45.3 .P107

Lyons, J., Hansen, S., Hurding, S., \& Elliott, D. (2006). Optimizing rapid aiming behaviour: Movement kinematics depend on the cost of corrective modifications. Experimental Brain Research, 174, 95-100. http:/ dx.doi.org/10.1007/s00221-006-0426-6

MacKenzie, S. I. (1992). Fitts' law as a research and design tool in human-computer interaction. Human-Computer Interaction, 7, 91-139. http://dx.doi.org/10.1207/s15327051hci0701_3

Mata, R., \& Nunes, L. (2010). When less is enough: Cognitive aging, information search, and decision quality in consumer choice. Psychology and Aging, 25, 289-298. http://dx.doi.org/10.1037/a0017927

Meyer, D. E., Abrams, R. A., Kornblum, S., Wright, C. E., \& Smith, J. E. K. (1988). Optimality in human motor performance: Ideal control of rapid aimed movements. Psychological Review, 95, 340-370. http:// dx.doi.org/10.1037/0033-295X.95.3.340

Pratt, J., Chasteen, A. L., \& Abrams, R. A. (1994). Rapid aimed limb movements: Age differences and practice effects in component submovements. Psychology and Aging, 9, 325-334. http://dx.doi.org/ 10.1037/0882-7974.9.2.325

Rey-Robert, B., Temprado, J.-J., \& Berton, E. (2011). Aging and changes in complexity in the neurobehavioral system. Medicina (Kaunas), 47, $1-10$.

Rey-Robert, B., Temprado, J.-J., Lemaire, P., \& Berton, E. (2012). Combining movement kinematics, efficiency functions, and Brinley plots to study age-related slowing of sensorimotor processes: Insights from Fitts' task. Gerontology, 58, 171-180. http://dx.doi.org/10.1159/000329347

Schäfer, S., Huxhold, O., \& Lindenberger, U. (2006). Healthy mind in healthy body? A review of sensorimotor-cognitive interdependencies in old age. European Review of Aging and Physical Activity, 3, 45-54. http://dx.doi.org/10.1007/s11556-006-0007-5

Schmidt, R. A., Zelaznik, H., Hawkins, B., Frank, J. S., \& Quinn, J. T., Jr. (1979). Motor-output variability: A theory for the accuracy of rapid motor acts. Psychological Review, 86, 415-451. http://dx.doi.org/ 10.1037/0033-295X.86.5.415

Shake, M. C., Noh, S. R., \& Stine-Morrow, E. A. L. (2009). Age differences in learning from text: Evidence for functionally distinct text processing systems. Applied Cognitive Psychology, 23, 561-578. http:/ dx.doi.org/10.1002/acp.1494

Siegler, R. S., \& Lemaire, P. (1997). Older and younger adults' strategy choices in multiplication: Testing predictions of ASCM using the 
induced loss of complexity and dedifferentiation: Consequences for coordination dynamics within and between brain, muscular and behavioral levels. Frontiers in Aging Neuroscience, 6, 140.

Sleimen-Malkoun, R., Temprado, J.-J., Huys, R., Jirsa, V., \& Berton, E. (2012). Is Fitts' law continuous in discrete aiming? PLoS ONE, 7(7), e41190. http://dx.doi.org/10.1371/journal.pone.0041190

Slifkin, A. B., \& Newell, K. M. (1999). Noise, information transmission, and force variability. Journal of Experimental Psychology: Human Perception and Performance, 25, 837-851. http://dx.doi.org/10.1037/00961523.25.3.837

Sosnoff, J. J., \& Newell, K. M. (2006). The generalization of perceptualmotor intra-individual variability in young and old adults. The Journals of Gerontology. Series B, Psychological Sciences and Social Sciences, 61, P304-P310. http://dx.doi.org/10.1093/geronb/61.5.P304

Spirduso, W. (2005). Physical dimensions of aging. Medicine and Science in Sports and Exercise, 28, 398-399.

Stine-Morrow, E. A. L., Miller, L. M. S., \& Hertzog, C. (2006). Aging and self-regulated language processing. Psychological Bulletin, 132, 582606. http://dx.doi.org/10.1037/0033-2909.132.4.582

Teasdale, N., Bard, C., Fleury, M., Young, D. E., \& Proteau, L. (1993). Determining movement onsets from temporal series. Journal of Motor Behavior, 25, 97-106. http://dx.doi.org/10.1080/00222895.1993 .9941644

Teeken, J. C., Adam, J. J., Paas, F. G. W. C., van Boxtel, M. P. J., Houx, P. J., \& Jolles, J. (1996). Effects of age and gender on discrete and reciprocal aiming movements. Psychology and Aging, 11, 195-198. http://dx.doi.org/10.1037/0882-7974.11.2.195

Temprado, J.-J., Sleimen-Malkoun, R., Lemaire, P., Rey-Robert, B., Retornaz, F., \& Berton, E. (2013). Aging of sensorimotor processes: A systematic study in Fitts' task. Experimental Brain Research, 228, 105-116. http://dx.doi.org/10.1007/s00221-013-3542-0 .org $/ 10.1177 / 001872088102300109$

Welford, A. T., Norris, A. H., \& Shock, N. W. (1969). Speed and accuracy of movement and their changes with age. Acta Psychologica, 30, 3-15. http://dx.doi.org/10.1016/0001-6918(69)90034-1

Welsh, T. N., Higgins, L., \& Elliott, D. (2007). Are there age-related differences in learning to optimize speed, accuracy, and energy expenditure? Human Movement Science, 26, 892-912. http://dx.doi.org/ 10.1016/j.humov.2007.04.004

Wisleder, D., \& Dounskaia, N. (2007). The role of different submovement types during pointing to a target. Experimental Brain Research, 176, 132-149. http://dx.doi.org/10.1007/s00221-006-0603-7

Woodworth, R. S. (1899). Accuracy of voluntary movement. The Psychological Review: Monograph Supplements, 3(3), i-114. http://dx.doi.org/ 10.1037/h0092992

Worringham, C. J. (1991). Variability effects on the internal structure of rapid aiming movements. Journal of Motor Behavior, 23, 75-85. http:// dx.doi.org/10.1080/00222895.1991.9941595

Yordanova, J., Kolev, V., Hohnsbein, J., \& Falkenstein, M. (2004). Sensorimotor slowing with ageing is mediated by a functional dysregulation of motor-generation processes: Evidence from high-resolution eventrelated potentials. Brain: A Journal of Neurology, 127, 351-362. http:// dx.doi.org/10.1093/brain/awh042

York, J. L., \& Biederman, I. (1990). Effects of age and sex on reciprocal tapping performance. Perceptual and Motor Skills, 71, 675-684. http:// dx.doi.org/10.2466/pms.1990.71.2.675

Received July 20, 2014

Revision received December 20, 2014 Accepted December 30, 2014 